\title{
La responsabilidad social del empleador (RSE) en Colombia frente a la discapacidad ${ }^{*}$
}

\author{
Recibido: 20 de febrero de 2019 • Aprobado: 23 de marzo de 2019 \\ https://doi.org/10.22395/ojum.v18n37a5
}

\author{
Angélica María Parra Báez"* \\ Liliana Andrea Vargas Espitia** \\ Olenka Woolcott Oyague
}

\section{RESUMEN}

En Colombia la responsabilidad social empresarial (RSE) ha tenido un lento avance. La mayoría de los empleadores carecen de conciencia colectiva que les permita entender su papel en la sociedad y la labor fundamental que realizan al generar puestos de trabajo, especialmente para aquellas personas en situación de discapacidad o con diversidad funcional. Desde la Corte Constitucional, ha sido señalado que el rol de la empresa y de la libertad de competencia debe contrastarse con la función social, en el marco de un Estado social de derecho. El presente artículo tiene por objeto revisar el papel de los empleadores en un mundo que hoy en día se debate entre la globalización, el fortalecimiento de bloques regionales y el nuevo nacionalismo, lo que genera formas diversas de trabajo, de trabajadores y de modalidades de contratación y amplía los conceptos tradicionales en el ámbito laboral donde cambia el verdadero papel del empresario en la inclusión de personas en situación de discapacidad.

Palabras clave: globalización; responsabilidad social; empleador; trabajador; discapacidad.

\footnotetext{
Artículo de investigación resultado del proyecto La parte débil en las relaciones jurídicas contemporáneas: un examen a partir de las relaciones jurídicas laborales, relaciones de consumo y el instituto de la responsabilidad civil respecto de las dificultades probatorias. Línea de investigación: estudios en derecho privado. Centro de Investigación: Francisco de Vittoria, Universidad Santo Tomás.

** Abogada, Universidad Santo Tomás, Bogotá, Colombia, especialista en Derecho de empresa y Derecho comercial, Universidad del Rosario, Bogotá, Colombia, magíster en Historia, Universidad Pedagógica y Tecnológica de Colombia, Bogotá, Colombia, docente Régimen Pensional Colombiano de la Universidad Santo Tomás. Correo electrónico: angelicaparra@usantotomas.edu.co. Orcid: https://orcid. org/0000-0003-4206-7206

*** Abogada, Universidad Santo Tomás, Bogotá, Colombia, especialista en Derecho Laboral, Pontificia Universidad Javeriana, Bogotá, Colombia, docente Derecho Colectivo Laboral de la Universidad Santo Tomás, coordinadora del Módulo Laboral y líder de investigación de la Universidad Santo Tomás. Correo electrónico: lilianavargas@usantotomas.edu.co. Orcid: https://orcid.org/0000-0003-4793-3011

"..* Doctora en Derecho de los Contratos y Obligaciones, Scuola Superiore S. Anna, Universidad de Pisa, Pisa - Italia, especialista en Derecho de los Negocios en la Unión Europea (IUSE), Turín, Italia, tutora de la Maestría en Derecho Contractual Público y Privado en la Universidad Santo Tomás. Correo electrónico: olenka.woolcott@gmail.com. Orcid: https://orcid.org/0000-0003-4709-2945
} 


\section{The Social Responsibility of the Employer (SRE) in Colombia on Disability}

\section{ABSTRACT}

In Colombia, the social responsibility of the employer (SRE) has had a slow development; most of the employers lack the collective consciousness that would allow them to understand their role in society, as well as the fundamental labor they perform by generating job positions, especially for those people with disabilities or diverse functionalities. The Constitutional Court has pointed out that the role of enterprises and freedom for competence must be contrasted with the social function in the framework of a Social State based on the Rule of Law. This article's main goal is reviewing the role of the employers in a world that debates around globalization, strengthening of regional blocks and new nationalism; which generates diverse manners of work, workers and contract modalities, while also widens the traditional concepts in the work framework, where the true role of the entrepreneur changes towards the inclusion of people with disabilities.

Keywords: globalization; social responsibility; employer; worker; disability.

\section{A responsabilidade social do empregador (RSE) na Colômbia ante a deficiência}

\section{RESUMO}

Na Colômbia, a responsabilidade social empresarial (RSE) apresenta um lento progresso. A maioria dos empregadores carece de consciência coletiva que lhes permita entender seu papel na sociedade e o trabalho fundamental que realizam ao gerar postos de trabalho, especialmente para as pessoas em situação de deficiência ou com diversidade funcional. A Corte Constitucional tem indicado que o papel da empresa e da liberdade de concorrência deve ser contrastado com a função social, no âmbito de um Estado social de direito. Este artigo tem o objetivo de verificar o papel dos empregadores em um mundo que hoje se debate entre a globalização, o fortalecimento de blocos regionais e o novo nacionalismo, o que gera formas diversas de trabalho, de trabalhadores e de modalidades de contratação, e amplia os conceitos tradicionais no contexto trabalhista em que se transforma o verdadeiro papel do empresário na inclusão de pessoas em situação de deficiência.

Palavras-chave: globalização; responsabilidade social; empregador; trabalhador; deficiência. 


\begin{abstract}
"Claro que es una enfermedad; en la práctica, un rechazo del otro porque es la aspiración completamente utópica de ir hacia sociedades racial, religiosa o ideológicamente homogéneas. Y eso no es democrático y, además, no es realista, porque todas las sociedades han evolucionado y se han diversificado extraordinariamente, que es lo que la globalización significa, un fenómeno del que nadie puede apartarse (...)"
\end{abstract}

Mario Vargas LLosa (Demichel, 2007).

\title{
INTRODUCCIÓN
}

En el marco del estudio de las diversas formas de contratación, como mecanismo de inclusión laboral para personas en situación de discapacidad' ${ }^{1}$ bajo el proyecto de investigación titulado La parte débil en las relaciones jurídicas contemporáneas: un examen a partir de las relaciones jurídicas laborales, relaciones de consumo y el instituto de la responsabilidad civil respecto de las dificultades probatorias, surgió la idea de poner de relieve el papel de los empleadores en la generación de empleo especialmente para personas con diversidades funcionales ${ }^{2}$, debido a la importancia que tiene su responsabilidad social en un mundo que abrió sus puertas a la globalización cambiando estructuras sociales, incluyendo las laborales, y que hoy día se debate entre la apertura feroz y el cierre de fronteras.

Aunque en este nuevo escenario, han existido esfuerzos legislativos nacionales e internacionales, encaminados a establecer incentivos al sector empresarial y en general a los empleadores para aumentar la demanda de perfiles ocupacionales compatibles con la población en condición de discapacidad, lo que se encuentra es que a la fecha no se ha logrado el impacto esperado.

Dichos esfuerzos, aunque loables, han sido insuficientes, ya que el desempleo en Colombia presenta altos índices. Al tratarse de personas en situación de discapacidad, el drama aumenta, lo que permite inferir que las dificultades para la población en condición de discapacidad, han creado también una brecha importante en la empleabilidad de esta. Por lo tanto, se consideró importante que, a través de una metodología descriptiva-analítica de revisión de conceptos, desarrollos normativos y aplicación práctica en la contratación laboral, se hiciera una revisión de la responsabilidad del empleador en la sociedad, el papel activo que debe tener para alcanzar los fines del Estado social de derecho y los compromisos que debe asumir en una sociedad altamente cambiante por los embates de la globalización, en un mundo donde los Estados, por un lado luchan por ampliar su visión al mundo y, por otro, se resisten a

\footnotetext{
1 Artículo titulado De las diversas formas de contratación, como mecanismo de inclusión laboral para personas en discapacidad de las mismas autoras. En revisión de pares para publicación.

2 Término surgido en el Foro de Vida independiente del año 2005 por el autor Javier Romañach.
} 
perder su soberanía, por lo que surge la necesidad de crear bloques regionales o de cierre de sus fronteras en pro de un nuevo nacionalismo.

Estos cambios, aunque no son nuevos, tienen trascendencia reciente y llevan a que las estructuras tradicionales se vean replanteadas, ya que al verse obsoletas, se pone de relieve la urgencia de sus ajustes, principalmente desde lo jurídico. Pese a ello, resulta evidente que cualquier modificación normativa debe ir acompañada de una conciencia social propia que lleve a alcanzar los fines de este Estado social de derecho, pues sin pretender un aislamiento del mundo, es clave que los empleadores tomen conciencia de su responsabilidad social en aras de ampliar la empleabilidad, especialmente de la población en situación de discapacidad o con diversidad funcional.

Con el objetivo fijado, se entrará en las próximas líneas a realizar una revisión conceptual de la globalización y, aunque sin entrar en un análisis propio del fenómeno, se analizará su impacto laboral, también se puntualizará qué se entiende por población en situación de discapacidad para posteriormente, y en una segunda parte, desarrollar propiamente la responsabilidad social del empleador.

\section{LA GLOBALIZACIÓN}

Frente a la globalización, se puede encontrar abundante literatura, pues en todas las áreas ha surgido la preocupación de estudiar su impacto, ya que aunque el proceso globalizador es un fenómeno histórico, solamente en las últimas décadas ha surgido el interés de su análisis, no siendo el campo del derecho ajeno a esta necesidad de revisar las implicaciones del fenómeno, máxime si se tiene en cuenta la recomposición de la definición tradicional del concepto de soberanía ${ }^{3}$.

Para ello vale la pena revisar algunas de sus acepciones, iniciando con el sociólogo Anthony Giddens quien la define como "la intensificación de las relaciones sociales a nivel mundial que vincula localidades distantes, de tal manera que los acontecimientos locales son modelados por eventos que tienen lugar a muchas millas de distancia y viceversa" (2000, p. 64).

De Sousa Santos (1998) asevera que la globalización es "un proceso selectivo, dispar, cargado de tensiones y contradicciones" (p. 56). Ulrich Beck (1988) plantea la existencia de una sociedad global con una multiplicidad de dimensiones que no

3 El autor Rafael Rubio trae a colación el impacto de la globalización en la idea de soberanía, dado que refiere cómo el proceso de globalización provoca la desintegración del Estado y la pérdida de confianza en las instituciones tradicionales, lo que conduce a la búsqueda de nuevas alternativas que encajen en una sociedad global (Rubio, 2007). 
requieren de un territorio vinculante, sino modos de vida que bajo el amparo de las redes de comunicación traspasen las fronteras del Estado nacional, lo cual replantea conceptos tradicionales como soberanía y nación.

También hay quienes se han ocupado del estudio de la globalización aclarando que no solo hace referencia a fenómenos internacionales, sino que también se vincula a las diversas sociedades nacionales en todos los ámbitos de existencia de la sociedad, lo que lleva a plantear que a nivel interno también se produce una movilización (Fazio, 2000).

Muchas son las definiciones y explicaciones metafóricas de la globalización. Ianni Octavio trae a colación frases de distintos autores como "aldea global", "fábrica global", "tierra patria", "primera revolución mundial", "tercera ola", "economía-mundo", "nueva división internacional del trabajo", "moneda global" (Ianni, 2006, p. 5), entre otras; todas estas bajo la significación de transformaciones que traen consigo la existencia de "nuevos" problemas por solucionar y donde la tecnología y las formas de comunicación adquieren un papel protagónico en el desarrollo del mundo, lo que plantea el reto de cimentar conciencia individual-colectiva nacional y mundial, dada precisamente la redefinición del espacio y el tiempo en aras de garantizar la producción global de bienes y sobretodo de servicios.

Retomando a Anthony Giddens, la globalización es fruto de una revolución en las telecomunicaciones que ha creado una audiencia global e innumerables redes de intercomunicación especializadas, desde las plataformas más sencillas pero masivas como las redes sociales hasta grandes y entramados sistemas de comunicación que conectan a toda la humanidad (Giddens, 2000).

Bajo estas definiciones y un sinnúmero que se dejaron de exponer, encontramos la profunda complejidad que encierra el fenómeno de la globalización, en su mayoría visto desde una dimensión económica, pero que claramente impacta a cada ser humano de este planeta, a las personas que como miembros de una comunidad se integran y deben ineludiblemente vivir conectados a los demás. Por eso también la globalización trae retos en la consideración de la persona como individuo-trabajador a quien le deben respetar sus derechos, los cuales están basados en principios humanos, pues este mundo económico voraz lleva a que el movimiento globalizador cause malestares, tal como lo refiere Stiglitz (2010) al señalar que:

La globalización puede ser rediseñada, y cuando lo sea, cuando sea manejada adecuadamente, equitativamente, cuando los países tengan voz en las políticas que los afectan, es posible que ello contribuya a crear una nueva económica global en la cual el crecimiento resulte no sólo más sostenible sino que sus frutos se compartan de manera más justa (p. 48). 
Y en esa búsqueda de justicia social en un mundo globalizado, en el que se observa la necesidad de superar la concepción de ciudadano local para pasar al de ciudadano planetario, el derecho, en todas sus áreas, entra a tener un papel fundamental como garante de los mínimos humanos, para nuestro objetivo valga revisar el impacto del fenómeno en materia laboral (García, Moreno y Rodríguez, 2015).

\subsection{La globalización laboral}

Como ha sido expuesto, la globalización ha marcado huellas en todos los sectores y en todos los aspectos de la vida. Para centrarnos, al revisar su impacto en el derecho laboral nos encontramos con el desafío de regular relaciones laborales desterritorializadas en modelos de Estado cuyo poder ha sido relativizado. Las migraciones también marcan pautas diversas en los modelos laborales que traspasan fronteras y legislaciones, por lo que el respeto por los derechos mínimos y la aplicación de principios humanos se constituyen en las fuentes de derecho que permiten su regulación, al flexibilizar la aplicación normativa.

Ulrich Beck resaltó que hay una evidente mundialización laboral, en la que se da una movilidad de los puestos de trabajo, ya que no existe la necesidad de que los operarios trabajen juntos en un lugar concreto para producir determinados bienes o servicios (Beck,1998, pp. 57-64). En este sentido se establece, como lo señala Francesco Galgano, una "expansión planetaria de la organización productiva" (2005, p. 31), haciendo referencia a la empresa transnacional que es controlada fuera de los límites nacionales (Galgano, 2005), o como lo denomina José Eduardo Faria (2001), una desterritorialización de la producción. En otras palabras, hay una revolución de los sistemas de producción y servicios, en el que el trabajo manual comienza a perder sentido tomando posiciones dominantes los trabajos intelectuales, y donde se adoptan estructuras descentralizadas en las que se privilegian las relaciones de colaboración, avances que abren caminos a la especialización flexible de la producción (Faria, 2001) bajo modelos posfordistas basados en el empleo directo de la tecnología que desarrolla conceptos del trabajador policualificado que sustituye la rígida visión laboral.

Por lo tanto, en un mundo abierto, suceden dos fenómenos que lo afectan: uno a nivel interno y el otro a nivel externo, el primero en el que la mente se globaliza exigiendo la existencia de más trabajadores formados para diferentes oficios, donde lo técnico no excluye lo intelectual y viceversa; el segundo, en el que además de las "empresas" supranacionales que se han formado dando cuenta de la globalización, a través de las multinacionales, también van surgiendo comunidades regionales que como lo señala Pipitone (1996): 
Se visualiza como un proceso complementario, o al menos paralelo, al proceso de globalización y que posee una contraparte expresada a través de un proyecto político denominado regionalismo o integración regional, la cual surge como una posibilidad de hacer frente a los problemas globales y también posibilita un mayor nivel de coordinación y formulación de objetivos comunes entre grandes áreas y esa afectación transtorna el mundo laboral y su distintas regulaciones (p. 105)

A partir de lo innegable de estos cambios, adquiere especial relevancia la flexibilidad, definida como esa capacidad de adaptación a las condiciones cambiantes de la demanda (Bilbao,1999), lo que genera la necesidad de adoptar novedosas formas de regulación de las relaciones contractuales relativas al trabajo, en sociedades donde la inclusión es un factor determinante en la consecución de los fines del Estado y en donde modelos discriminatorios de segregación o sustitución cada vez son más condenados.

Se ve reflejada la intensa lucha que los individuos, integrantes de distintas sociedades están soportando, ya que sin que sea tema para tratar en este escrito, además hoy se están identificando sacudidas nacionalistas internas de los antiguos Estados nacionales, lo que genera una serie de contradicciones en donde adquieren importancia no solo los mandatos legales, sino además la exaltación de la esencia del ser humano, la conciencia, término que puede resultar ambiguo pero que según lo estudió Álvarez Munárriz (2005), se entiende como:

Una capacidad global de la mente humana que nos proporciona un saber acerca de nosotros mismos y de nuestra situación en el mundo (...) En este proceso evolutivo la conciencia constituye un punto singular que paraliza los comportamientos innatos para establecer redes de relación. Las redes de relación son claves en el proceso de hominización y humanización (p. 11).

Y justamente, desde la humanización surge la necesidad de generar empatía con el otro, entender que solo se es más humano si comprendo que el otro debe también tener mis mismos derechos y deberes, de ahí que surja la importancia de considerar la responsabilidad social de los empresarios para generar mayor empleabilidad máxime si se trata de personas en situación de discapacidad o, como se verá más adelante, personas con diversidades funcionales.

\subsection{Empleados en situación de discapacidad o con diversidad funcional}

En esa visión de un mundo globalizado, y continuando con este hilo descriptivo, la Organización de Naciones Unidas aprobó la Convención sobre los derechos de las personas con discapacidad en el año 2006, reconociendo que el concepto de discapacidad es cambiante "evoluciona y que resulta de la interacción entre las personas con deficiencias 
y las barreras debidas a la actitud y al entorno que evitan su participación plena y efectiva en la sociedad, en igualdad de condiciones con las demás".

La convención, basándose en el modelo social, considera que las causas de la discapacidad son sociales, es decir, la sociedad es la que genera la discapacidad, por lo tanto su inclusión radica en la eliminación de obstáculos y tratamientos no diferenciados con el resto de personas (Palacios, 2008). Personas con discapacidad en las que se incluyen aquellas con desviaciones significativas del promedio de la población, ya sean físicas, mentales, intelectuales o sensoriales, y que constituyen un grupo poblacional que históricamente ha recibido distintas denominaciones (Colectivo Ioé, 2013), que han sido reconocidos como incapaces/inválidos o minusválidos y más recientemente como discapacitados, términos que aún tienen vigencia en las normas laborales aplicadas en Colombia y que pueden tener valoraciones negativas al señalar que se trata de imperfecciones respecto de patrones a normalidad.

Ahora bien, y dado que el Foro de Vida Independiente ${ }^{4}$, al analizar que dicho grupo poblacional no carece de capacidades, sino que funciona de una manera que no es la habitual, sugirió el término, muy aceptado, de "diversidad funcional", el cual describe que las personas con discapacidad pueden desempeñar las mismas funciones que cualquier persona, pero lo hacen de un modo distinto al que se considera como usual: no carecen de nada, pueden hacer lo mismo que cualquiera, pero de una manera diferente (mismas funciones, diverso modo de realizarlas) (Ferreira, 2010).

A partir de ese cambio de paradigma de consideración de la discapacidad, en el que se pasa de una concepción en la que las personas con limitaciones es, privada de su capacidad de representación lo que la priva de derechos civiles y políticos, a una en la que se les acepta plenamente capaces e independientes. La sociedad tiene la responsabilidad de su acompañamiento y protección, así lo entendió el Congreso Colombiano al aprobar la convención de la ONU con la Ley 1346 de 2009. Esto es, Colombia aceptó la tarea real de implementación normativa y el desarrollo de principios acordes al Estado social de derecho en los que se materialicen los ideales de inclusión social, igualdad y libertad, en los cuales se rompan las barreras que puedan impedir la participación plena y efectiva en la sociedad de todos los actores sin discriminación.

Así las cosas, en materia laboral, en el artículo 27 de la citada Ley 1346 de 2009, se dispuso el reconocimiento de los derechos de las personas con discapacidad a trabajar en igualdad de condiciones en entornos laborales que sean abiertos, inclusivos

${ }^{4} \quad$ El Foro de Vida Independiente y Divertad tiene su origen a mediados del año 2001 con el objetivo de impulsar en España el movimiento de Vida Independiente, surgido en Estados Unidos en 1972 y muy arraigado en Europa (Foro de Vida Independiente y Divertad, 2009). 
y accesibles ${ }^{5}$. Lo que adquiere relevancia dado que el derecho al trabajo "se encuentra íntimamente relacionado con la asunción de ciertos valores intrínsecos a los derechos humanos, y aspira a potenciar el respeto por la dignidad humana, la igualdad y la libertad personal, propiciando la inclusión social" (Palacios, 2008, p. 473).

Postulados del derecho al trabajo que, a partir de sus principios, se deben ver dinamizados y mundializados, dado que con:

Los principios del derecho social se ha recurrido al reconocimiento constitucional; a los consensos sociales construidos por el juez constitucional con los intereses alegados por las partes y decantados hasta ese momento; al peso del bloque de constitucionalidad (...) que enriquece el ordenamiento jurídico interno con postulados universales y a los valores supremos defendidos en una sociedad (Goyes Moreno e Hidalgo Oviedo, 2012).

Esta cita recuerda la necesidad de fijar posturas y encaminar contractualmente las relaciones laborales basadas en la justicia, la inclusión y el respeto de los valores, derechos y principios humanos.

Resulta claro que, a nivel mundial, se reconoce la importancia que en la empleabilidad se incluyan sin ninguna restricción a todos los miembros de la sociedad, es decir, se trata de que en esta conformación de las nuevas sociedades mundiales o regionales, no haya ningún tipo de exclusión. El planeta ya se ha pronunciado normativamente, ahora le corresponde a cada empleador aplicar dichos postulados en las relaciones laborales y de trabajo que se establezcan.

No obstante, y a pesar de los cambios en la teoría jurídica, se observa que en nuestras realidades se imponen grandes barreras en la empleabilidad, especialmente de las personas con diversidades funcionales, ejemplo de ello lo trajeron a colación Verdugo, Yepes, Paz, Sanchez y Monico (2016), al señalar que "las probabilidades de emplearse de forma digna en Colombia para una persona con discapacidad visual son bajas con respecto al general de la población". Esta aseveración que lleva a revisar la segunda parte de nuestra propuesta relacionada con la responsabilidad de los empleadores en el mundo y en Colombia, de emplear con conciencia social, especialmente a aquellas personas que presentan estas diversidades funcionales.

5 Ley 1346 de 2009, artículo 27 "Los Estados Partes reconocen el derecho de las personas con discapacidad a trabajar, en igualdad de condiciones con las demás; ello incluye el derecho a tener la oportunidad de ganarse la vida mediante un trabajo libremente elegido o aceptado en un mercado y un entorno laborales que sean abiertos, inclusivos y accesibles a las personas con discapacidad. Los Estados Partes salvaguardarán y promoverán el ejercicio del derecho al trabajo, incluso para las personas que adquieran una discapacidad durante el empleo, adoptando medidas pertinentes, incluida la promulgación de legislación". 


\section{LA RESPONSABILIDAD SOCIAL EMPRESARIAL (RSE) A NIVEL MUNDIAL}

La responsabilidad social empresarial obedece a un concepto que ha tomado gran fuerza a la hora de calificar y clasificar a las empresas según el impacto, conciencia y rol que juegan en el entorno social en que desarrollan sus actividades. Sin embargo, en la historia del concepto se distinguen tres etapas diferenciadas (Correa, 2007), a saber:

La fase inicial: desde finales del siglo XIX hasta principios del XX, lapso en el cual no existe un concepto sólido o comúnmente aceptado sobre la RSE, con algunas empresas e industrias desarrollando actividades desde la filantropía y la caridad.

La segunda etapa: desarrollada en la segunda mitad del siglo XX, en el cual, de manera mancomunada y organizada, las empresas desarrollaron un criterio más social para el bienestar común y el entorno que las rodean.

La tercera etapa: el Estado y el mercado realizan una interrelación y colaboración, a partir de desarrollos normativos más restrictivos de las prácticas empresariales, que permiten la inclusión de grupos de interés y organizaciones de diversa índole en la formulación de compromisos ante las necesidades identificadas en la sociedad.

Lo anterior nos permite establecer que, si bien ha existido cierta conciencia respecto del rol social de las empresas como representantes del mercado desde los albores del capitalismo, las acciones inspiradas en este han sido desarticuladas y desorganizadas, a tal punto que no se ha generado en las legislaciones internas de los países una estructuración completa del concepto mismo de la RSE, que conlleve a mayor efectividad en su aplicación.

Diferentes organizaciones financieras internacionales han emitido definiciones sobre el concepto de la RSE, entendida como: "Hacer negocios basados en principios éticos y apegados a la ley. La empresa (no el empresario) tiene un rol ante la sociedad, ante el entorno en el cual opera" (Banco Mundial, 2006, p. 1). No obstante, solo hasta la década de los 90, en el marco del Foro Mundial de Davos, Suiza, en el que se anunció el Pacto mundial de Naciones Unidas, puesto en práctica en el año 2000, se estipularon principios universales de derechos humanos, normas laborales y medioambientales aplicables a las actividades empresariales. De esa forma surgió un nuevo enfoque en el concepto del desarrollo de la empresa y el desarrollo económico, que entiende la RSE como "la incorporación consciente, clara y sostenida en la gestión estratégica de la organización, de los impactos sociales de su actividad en el entorno" (Expósito, 2008). Es una visión de negocios que integra el respeto por las personas, los valores éticos, la comunidad y el medioambiente con la gestión misma de la empresa independientemente de los productos o servicios que ofrezca (Aliarse, s.f.). 
La anterior definición reúne las primigenias actividades de las empresas y recoge los esfuerzos conscientes de las organizaciones humanas de ampliar el rol de la unidad productiva, más allá de la mera rentabilidad económica, procurando de esta forma impactar socialmente en pro del bien general. No obstante, dicho rol resulta en muchas oportunidades difícil de optimizar dado que no genera en los empresarios el interés suficiente para impactar en todos los grupos poblacionales, sino solo en aquellos que les reporten mayor rentabilidad.

Si bien las empresas tienen como objetivo generar rentabilidad, normalmente se presenta la circunstancia de que estas no toman en cuenta los beneficios que tiene actuar bajo los postulados de la RSE, dado que estos no son cuantitativos, sino cualitativos (Sen, 2000), haciendo de esta manera poco eficaz el objetivo mismo de la responsabilidad que se encuentra a su cargo.

Tal situación se evidencia en personas en situación de discapacidad, mujeres embarazadas, personas de avanzada edad, entre otros grupos poblacionales, los cuales presentan serias dificultades de empleabilidad bajo el estigma de ser poco productivos, circunstancia que no guarda relación con el objetivo mismo de la RSE y el impacto que debe tener en la sociedad. Y es por ello que la RSE corresponde a un compromiso tanto dentro de la empresa como fuera de la misma, por medio de la cual se busca satisfacer no solo expectativas de orden económico y ambiental sino también fortalecer valores eticos y de respeto de quienes conformar la sociedad a fin de obtener el bien común.

Lo anterior implica que de cara a la RSE, el concepto mismo de empresa amplía sus límites, contemplando no solo el crecimiento cuantitativo económico, sino también "la libertad de los individuos de poder elegir y la sociedad debe brindar las oportunidades, para que cada individuo, decida ser él mismo, no a partir de lo obligado, o de lo que pueda, o de lo que desee" (Cardona, 2016, p. 10). En el caso particular de las personas en situación de discapacidad, las cuales corresponden aproximadamente a mil millones en todo el mundo, de acuerdo con los datos de la OIT, más del $80 \%$ de dicha cifra se encuentra desempleada (Defensoría del Pueblo de la Municipalidad de San Carlos Bariloche, s.f.), lo que demuestra una realidad diferente frente a la puesta en marcha de la RSE a nivel mundial.

Es claro que Este grupo poblacional está esperando una oportunidad laboral para demostrar sus capacidades y competencias, mejorar su calidad de vida y consecuencialmente aportar al mundo productivo (Ministerio de Trabajo y Best Buddies Colombia, 2016). Sin embargo, ello no será posible mientras las empresas no adopten una política inclusiva que permita desarrollar el verdadero objetivo de la RSE. 
Ahora bien, la Organización Internacional para la Normalización (ISO, por sus siglas en inglés), ha emitido la norma ISO 26000, la cual contiene el objeto, campo de aplicación, los términos y definiciones de la figura de la responsabilidad social, extrapolable a las empresas y organizaciones de todo tipo. Los principios sobre los cuales se funda dicha norma ISO se orientan a la transparencia de las organizaciones, públicas o privadas, el comportamiento ético, respeto a los derechos humanos, y particularmente a las prácticas laborales de los empresarios.

En ese sentido, la norma pretende generar varios beneficios a las empresas que la implementen, como, por ejemplo, mejorar la reputación de la empresa ante la sociedad, aumentar la ventaja competitiva, aportar capacidad para motivar y promover el compromiso y la productividad de los trabajadores, y mejorar las relaciones entre las empresas, los gobiernos y demás actores sociales. Y es precisamente el elemento cualitativo el que hace que la RSE sea una herramienta importante para hacer efectivas las políticas públicas de inclusión laboral de personas en situación de discapacidad, como manifestación del compromiso de las empresas hacia la sociedad en general y de la aplicación de la legislación existente.

\section{LA RESPONSABILIDAD SOCIAL EMPRESARIAL EN COLOMBIA}

En Colombia, el Instituto Colombiano de Normas Técnicas y Certificación (Icontec) define la RSE como:

Compromiso voluntario y explícito que las organizaciones asumen frente a las expectativas y acciones concertadas que se generan con las partes interesadas en materia de desarrollo humano integral; esta permite a las organizaciones asegurar el crecimiento económico, el desarrollo social y el equilibrio ambiental, partiendo del cumplimiento de las disposiciones legales (2008, p. 1).

Sin embargo, la norma técnica anterior no forma parte del ordenamiento jurídico strictu sensu, por lo cual es necesario establecer en principio el sustrato normativo constitucional para el desarrollo jurídico interno de dicha definición.

Podemos justamente encontrar dicho fundamento en el artículo 333 de la Constitución Política de Colombia, que se cita para efectos de encaminar el análisis de la figura en el ordenamiento jurídico nacional, así:

La acividad económica y la iniciativa privada son libres, dentro de los límites del bien común. Para su ejercicio, nadie podrá exigir permisos previos ni requisitos, sin autorización de la ley.

La libre competencia económica es un derecho de todos que supone responsabilidades. 
La empresa, como base del desarrollo, tiene una función social que implica obligaciones. El Estado fortalecerá las organizaciones solidarias y estimulará el desarrollo empresarial.

El Estado, por mandato de la ley, impedirá que se obstruya o se restrinja la libertad económica y evitará o controlará cualquier abuso que personas o empresas hagan de su posición dominante en el mercado nacional.

La ley delimitará el alcance de la libertad económica cuando así lo exijan el interés social, el ambiente y el patrimonio cultural de la Nación (subraya fuera del texto).

Lo anterior demuestra que la Constitución Política de Colombia de 1991 ya había planteado la figura de la función social de las empresas dentro de los límites del bien común, sin embargo, la norma no establece las formas en que debe hacerse efectiva dicha función, es clara la existencia de un vacio en la legislación interna. No obstante, desde el escenario normativo colombiano, existen diferentes normas encaminadas o fundamentadas en el anterior concepto de responsabilidad social empresarial, que han estado orientadas de manera genérica a tres frentes: derechos humanos; normatividad laboral y medio ambiente.

Así mismo, la RSE tiene diferentes objetivos, sin embargo, respecto de las personas en situación de discapacidad, se puede entender como el actuar voluntario de las empresas para cumplir la legislación nacional para evitar así actos de discriminación respecto de dicho grupo representativo, lo que implica un especial compromiso con la diversidad. Lo anterior genera en el empresario la identificación clara de un grupo de interés que podrá aprovecharse en los diferentes procesos internos y externos haciendo uso del potencial humano que ello le puede representar.

Dado que una forma de hacer efectiva la responsabilidad social empresarial es a través de estrategias de inclusión laboral, desde el ámbito de las personas en situación de discapacidad, enunciamos a manera puramente ilustrativa algunas de las normas que han abordado el tema:

- Constitución Política de Colombia, artículos 13, 47, 54 y 68, por medio de la cual se garantiza la igualdad y se establece la obligación del Estado y de los empleadores de garantizar a los minusválidos el derecho a un trabajo acorde con sus condiciones de salud.

- Convenio 159 de 1989, de la Organización Internacional del Trabajo por medio del cual se abordan temas de rehabilitación profesional y empleo.

- Ley 361 de 1997, por la cual se establecen mecanismos de integración social de las personas en situación de discapacidad y se dictan otras disposiciones. 
- Ley 762 de 2002, por medio de la cual se aprueba la Convención Interamericana para la eliminación de las formas de discriminación contra las personas en situación de discapacidad.

- Ley 1145 de 2007, por medio de la cual se organizó el Sistema Nacional de Discapacidad, con el objetivo de impulsar la formulación de políticas públicas de manera conjunta entre las entidades públicas del orden nacional, regional y local.

- Ley 1306 de 2009, por medio de la cual se busca proteger a las personas en situación de discapacidad mental y se establece el régimen de representación legal de incapaces emancipados.

- Ley 1429 de 2010, parágrafo 5 del artículo 3, en el cual se establece que los programas de formación y capacitación serán prioritarios para jóvenes con discapacidad.

- Ley Estatutaria 1618 de 2013, por medio de la cual se establecen las disposiciones para garantizar el pleno ejercicio efectivo de los derechos de las personas con discapacidad, mediante la adopción de medidas de inclusión, acciones afirmativas y ajustes razonables.

- Ley 1680 de 2013, por la cual se garantiza a las personas ciegas y con baja visión, el acceso a la información, a las comunicaciones, al conocimiento y a las tecnologías de la información y de las comunicaciones.

- Ley 1752 de 2015, por medio de la cual se modifica la Ley 1482 de 2011, que sanciona penalmente la discriminación contra las personas en situación de discapacidad.

- Ley 1901 de 2018, por medio de la cual se crean y desarrollan las sociedades comerciales de Beneficio e Interés Colectivo (BIC).

Las anteriores normas de rango constitucional y legal contienen beneficios tributarios, licitatorios, bonificación en el puntaje en procesos de contratación pública, entre otros, pero no desarrollan de manera integral los postulados que ya han sido desarrollados por la jurisprudencia, referentes a la RSE. En ese orden de ideas, es relevante mencionar que la Corte Constitucional estudió el papel de la empresa en la comunidad, dado que sus acciones pueden repercutir positiva y negativamente en la misma, por lo que resaltó el papel de la Responsabilidad Social Empresarial indicando que:

Los programas de responsabilidad social responden a la necesidad de que la empresa, en cuanto sujeto que actúa al interior de la sociedad, sea partícipe del 
desarrollo y promotor del bienestar del sujeto colectivo en que se lleva a cabo su actividad (Corte Constitucional de Colombia, 2010a).

Lo anterior demuestra claramente que la intención de la RSE es que con el actuar de las empresas se logre impactar de manera positiva en todas las esferas de la sociedad, y una manera efectiva de hacerlo puede ser plantear opciones de empleabilidad para personas en situación de discapacidad, como alternativa para materializar la democracia participativa en igualdad de condiciones.

Desde el Ministerio de Trabajo y Best Buddies Colombia (2016), se sostiene que las empresas que realizan inclusión laboral de personas en situación de discapacidad, son conscientes del beneficio que ello les reporta y contemplan de manera clara en su estrategia corporativa la diversidad, haciendo de esta forma efectiva su obligación ética. No obstante la intención y las diversas normas que han intentado abordar el tema, es una realidad que la situación de discapacidad genera no solo dificultad para acceder a un empleo digno sino para permanecer en él, como consecuencia del temor y falta de cultura empresarial. Es por ello que la misma corporación, con ocasión del examen de constitucionalidad de la norma aprobatoria del Tratado de Libre Comercio entre Canadá y Colombia, señaló:

La Corte considera de la mayor importancia que los postulados de la llamada responsabilidad social corporativa (RSC) o responsabilidad social empresarial (RSE) sean elevados a derecho positivo internacional convencional, por cuanto sus fuentes normativas suelen encontrarse en disposiciones de soft law, tales como declaraciones y resoluciones. En tal sentido, incluir los principios de la RSC en un tratado de libre comercio como el presente, coadyuva al cumplimiento de los valores y principios constitucionales tales como la solidaridad, la dignificación del trabajo, el respeto por el medio, y en general, el cumplimiento de las obligaciones de las empresas en materia de derechos humanos (Corte Constitucional de Colombia, 2010b) (subraya fuera del texto).

Como puede observarse, el panorama jurídico interno de Colombia respecto de la RSE no está desarrollado de manera consciente ni integral, sino que resulta ser objeto de estudio al momento de examinar casos específicos, y no como política de Estado que pueda hacerse extensiva y obligatoria a todo el sector empresarial.

La inclusión laboral, como manifestación de la responsabilidad social implica una decisión gerencial, que a su vez conlleva a: i) dar una garantía de que la inclusión va a permear a toda la organización, ii) plantear una estrategia o política empresarial a desarrollar y no simplemente que obedezca a una iniciativa aislada, iii) incidir sobre todas las áreas de la organización y iv) realizar una evaluación del impacto y los 
resultados que conlleva la contratación de personas en situación de discapacidad ${ }^{6}$ (Ministerio de Trabajo y Best Buddies Colombia , 2016).

Ahora bien, en el marco de la globalización, se ha observado una flexibilización laboral (Stiglitz, 2010), que parte de dos fenómenos o mecanismos paralelos: la liberalización del insumo capital (que mencionamos en el estudio de la globalización laboral como inversión extranjera directa) y la flexibilidad del mercado de trabajo propiamente dicha. La región latinoamericana, si bien demostró un pobre resultado de lo que se pretendía con las políticas de la globalización, especialmente respecto del crecimiento económico, la tendencia hacia la flexibilización fue palmaria. El Programa Regional del Empleo para América Latina y El Caribe (Prealc), afirma que entre 1980 y 1989, el mercado de trabajo en la región estuvo marcado por una reducida seguridad en el empleo, con el cambio de jornada completa a jornada parcial, y el aumento en la utilización de la subcontratación (Infante y Klein, 1991).

En Colombia, el panorama se ha mantenido en esa línea, e incluso se ha agudizado, a partir de cuatro fenómenos paralelos que intensifican los impactos de la globalización económica en la desprotección laboral: i) privatización, ii) tercerización, iii) informalización y iv) precarización, todas enmarcadas en las nuevas legislaciones laborales (Guevara, 2003, p. 106).

Es importante mencionar que, desde el ámbito normativo laboral, se han establecido figuras como los fueros, la estabilidad laboral reforzada y ciertas prohibiciones y deberes en cabeza de los empleadores con el objetivo de proteger a la población en condición de discapacidad. Sin embargo, se insiste, la solución no ha sido integral y menos ha sido considerada la RSE como fundamento para realizar mayores desarrollos jurídicos en el asunto.

De acuerdo con la Ley Estatutaria 1618 de 2013, la inclusión es un proceso que asegura que todas las personas tengan las mismas oportunidades y la posibilidad real y efectiva de acceder, participar, relacionarse y disfrutar de un bien, servicio o ambiente, junto con los demás ciudadanos, sin ninguna limitación o restricción por motivo de discapacidad, mediante acciones concretas que ayuden a mejorar la calidad de vida de personas en situación de discapacidad (Ministerio de Trabajo y Best Buddies Colombia , 2016). A pesar de lo anterior, los empresarios manifiestan que en Colombia existen desarrollos jurisprudenciales contradictorios y excesivamente proteccionistas hacia los trabajadores, lo que necesariamente conlleva a ver la inclusión laboral de

6 El paso a paso de la inclusión laboral involucra tanto a la empresa como a la persona en situación de discapacidad y cuenta con cinco pasos cuales son: 1. Decisión gerencial, 2. Selección y contratación, 3. Sensibilización, 4. Acompañamiento y 5. Evaluación (Ministerio de Trabajo y Best Buddies Colombia, 2016). 
personas en situación de discapacidad como una carga que desde ningún punto de vista les genera beneficios, y es precisamente dicha percepción la que impide que las organizaciones adopten medidas o políticas que materialicen la responsabilidad social que les compete.

Lo anterior puede ser considerado como una oportunidad para hacer efectivas las políticas públicas ya existentes, en coadyuvancia con la actividad legislativa y jurisdiccional del Estado y así intentar la superación de la brecha de empleabilidad de la población en condición de discapacidad, con la participación activa y no estereotipada de los empresarios que equivocadamente conciben la vinculación de las personas en situación de discapacidad como una carga y no un beneficio.

Para lograr el objetivo, es necesario llevar a cabo un proceso de sensibilización en el que se reconozca la discapacidad como diversidad de cara a los principios constitucionales y de esta forma se generen espacios en donde se valoren las habilidades y competencias de las personas en dicha situación y se promueva el respeto a la dignidad humana y el trato laboral en igualdad de condiciones.

Así las cosas, partiendo de las políticas públicas nacionales e internacionales ya existentes, la ley, la jurisprudencia y la iniciativa gerencial podrán construirse los cimientos de una política exclusiva de RSE, tendiente a generar mecanismos de inclusión de las personas en situación de discapacidad y de otros grupos poblacionales, cumpliendo el verdadero objeto de dicha función social que se verá reflejada en el bien común.

\section{CONCLUSIONES}

La globalización es un fenómeno que ha estado presente desde tiempos antiguos, sin embargo la importancia de su estudio ha adquirido relevancia reciente, precisamente por el impacto y los efectos que causa en nuestras realidades, generando nuevas situaciones, que a nivel laboral se explican desde la flexibilización de la producción, las formas de producir, la preponderancia de los servicios sobre los bienes, la tecnificación de los procesos, la relativización del uso formal de la mano de obra en los procesos, la movilización de los trabajadores y las distintas y novedosas formas de contratación laboral.

En este planeta mundial se visualiza la importancia de que toda la sociedad participe en igualdad de condiciones, sin discriminaciones o exclusiones a causa de posibles situaciones de discapacidad, adquiriendo especial relevancia la implementación del modelo social, en el cual la sociedad tiene el deber y la responsabilidad de generar un ambiente inclusivo para toda la población, sin que interese su situación de discapacidad. 
En general, no existe la discapacidad como un término que de forma negativa señala un valor menor al normal, existen personas con diversidad funcional que pueden laborar de manera distinta, corresponde entonces permitir su acceso al mundo laboral en aras de cumplir con los postulados de inclusión y no discriminación.

Desde lo laboral, corresponde a los empresarios y empleadores generar oportunidades de empleabilidad para toda la población en general, pero en especial para las personas con diversidades funcionales como una estrategia que permita el desarrollo sostenible de los países, que tiene un alto impacto a nivel mundial; la capacidad no siempre se refleja de la misma forma, sino que existen diferencias positivas que permiten los mismos desarrollos pero ejecutados de distinta forma.

Resulta completamente necesario reglamentar la legislación existente a fin de lograr el cumplimiento efectivo de la RSE y así optimizar la función social de las empresas nacionales y extranjeras.

Es indispensable, para lograr el objetivo de la RSE, sensibilizar a los empresarios a fin de que adopten en las organizaciones políticas o medidas de impacto y no simples iniciativas aisladas en pro de la inclusión laboral de personas en situación de discapacidad como aceptación a la diversidad.

Se hace necesario visibilizar el impacto y los resultados positivos que puede conllevarle a las empresas la puesta en marcha de políticas de inclusión laboral, lo cual podría generar interés de los empresarios de acceder de manera efectiva a los beneficios establecidos en la legislación nacional.

En aras de proporcionar seguridad jurídica a los empresarios nacionales y extranjeros, se requiere del compromiso de los operadores judiciales a fin de evitar desarrollos jurisprudenciales contradictorios que generan confusión y consecuencialmente poca intención de aplicar en debida forma la RSE.

Se requiere diseñar campañas de socialización de las políticas públicas nacionales e internacionales relacionadas con la RSE, con el fin de obtener mayor compromiso por parte de los empresarios en temas laborales y así lograr impactar de manera positiva en grupos poblacionales con alto porcentaje de discriminación.

\section{REFERENCIAS}

Alianza por la Responsabilidad Social Empresarial por México .Aliarse. (s.f.). Definición RSE y ventajas. Recuperado de http://www.aliarse.org.mx/rse.html

Álvarez Munárriz, L. (2005). La conciencia humana: perspectiva cultural. En L. Álvarez Munárriz y E. Couceiro (Coords.), La conciencia humana: perspectiva cultural (pp. 11-92). Barcelona: Anthropos. 
Asamblea General de las Naciones Unidas. (2006). Convención sobre los derechos de las personas con discapacidad. Recuperado de https://www.un.org/esa/socdev/enable/documents/tccconvs.pdf

Banco Mundial. (2006). ¿Qué es RSE? Recuperado de https://siteresources.worldbank.org/CGCSRLP/ Resources/Que_es_RSE.pdf

Beck, U. (1998). ¿Quées la globalización? Falacias del globalismo, respuestas a la globalización. Barcelona: Paidós.

Bilbao, A. (1999). La globalización y las relaciones laborales. Cuadernos de Relaciones Laborales, (15), 123-137.

Cardona, D. (2016). La responsabilidad social empresarial: concepto, evolución y tendencias. Recuperado de http://www.unilibre.edu.co/bogota/pdfs/2016/1sin/25.pdf

Colectivo Ioé. (2013). Diversidad funcional en España. Hacia la inclusión en igualdad de las personas con discapacidades. Revista Española de Discapacidad, 1(1), 33-46.

Infante, R. y Klein, E. (1991). Mercado latinoamericano del trabajo en 1950-1990. Revista de la Cepal, (45), 129-143.

Congreso de la República. Colombia. (1997). Ley 361 febrero 7 por la cual se establecen mecanismos de integración social de las personas en situación de discapacidad y se dictan otras disposiciones. Diario Oficial 42.978 de febrero 11 de 1997.

Congreso de la República. Colombia. (2002). Ley 762 julio 31 por medio de la cual se aprueba la Convención Interamericana para la Eliminación de todas las formas de Discriminación contra las Personas con Discapacidad, suscrita en la ciudad de Guatemala, Guatemala, el siete (7) de junio de mil novecientos noventa y nueve (1999). Diario Oficial 44.889 de agosto 5 de 2002.

Congreso de la República. Colombia. (2007). Ley 1145 julio 10 por medio de la cual se organiza el Sistema Nacional de Discapacidad y se dictan otras disposiciones. Diario Oficial 46.685 de julio 10 de 2007.

Congreso de la República. Colombia. (2009). Ley 1306 junio 5 por medio de la cual se dictan normas para la Protección de Personas con Discapacidad Mental y se establece el régimen de la representación legal de incapaces emancipados. Diario Oficial 47.371 de junio 5 de 2009.

Congreso de la República. Colombia. (2010). Ley 1429 diciembre 29 por la cual se expide la Ley de formalización y generación de empleo. Diario Oficial 47.937 de diciembre 29 de 2010.

Congreso de la República. Colombia. (2013). Ley Estatutaria 1618 febrero 27 por medio de la cual se establecen las disposiciones para garantizar el pleno ejercicio de los derechos de las personas con discapacidad. Diario Oficial 48.717 de febrero 27 de 2013.

Congreso de la República. Colombia. (2013). Ley 1680 noviembre 20 por la cual se garantiza a las personas ciegas y con baja visión, el acceso a la información, a las comunicaciones, al conocimiento y a las tecnologías de la información y de las comunicaciones. Diario Oficial 48.980 de noviembre 20 de 2013. 
Congreso de la República. Colombia. (2015). Ley 1752 junio 3 por medio de la cual se modifica la Ley 1482 de 2011, para sancionar penalmente la discriminación contra las personas con discapacidad. Diario Oficial 49.531 de junio 3 de 2015.

Congreso de la República. Colombia. (2018). Ley 1901 junio 18 por medio de la cual se crean y desarrollan las sociedades comerciales de Beneficio e Interés Colectivo (BIC). Diario Oficial 50.628 de junio 18 de 2018.

Constitución Política de Colombia. (1991). Gaceta Constitucional n. 116 de julio 20 de 1991.

Correa, J. G. (2007). Evolución histórica de los conceptos de responsabilidad social empresarial y balance social. Semestre Económico, 10(20), 87-102.

Corte Constitucional. (2010a). Sentencia T-247 de abril 15. M. P. Sierra Porto, H.

Corte Constitucional. (2010b). Sentencia C-608 de agosto 3. M. P. Sierra Porto, H.

Defensoría del Pueblo Municipalidad de San Carlos de Bariloche. (s.f.). El 80 \% de las personas con discapacidad están desempleadas. Recuperado de http://www.defensoriabariloche.gob.ar/el-80 de-las-personas-con-discapacidad-estan-desempleadas/

Demicheli, T. (20 de mayo de 2007). Mario Vargas Llosa: «El PSOE se ha vuelto el caballo de Troya de los nacionalismos». ABC. Recuperado de https://www.abc.es/cultura/abci-mario-vargas-llosapsoe-vuelto-caballo-troya-nacionalismos-200705200300-1633215408442_noticia.html

De Sousa Santos, B. (1998). La globalización del derecho: los nuevos caminos de la regulación y la emancipación. Bogotá: Universidad Nacional de Colombia e Instituto Latinoamericano de Servicios Legales Alternativos.

Expósito, R. (2008). Responsabilidad social empresarial -RSE. Naturaleza, historia y evolución. En Proyecto Bolívar Emprende 150 años (Ed.), Responsabilidad social empresarial para emprendedores (pp. 15-24). Cartagena: Fundación Colombia Emprende.

Faria, J. E. (2001). El derecho en la economía globalizada. Madrid: Trotta.

Fazio, H. (2000). Una mirada braudeliana a la globalización. Convergencia, Revista de Ciencias Sociales, (21), 11 47.

Ferreira, M. A. (2010). De la minus-valía a la diversidad funcional: un nuevo marco teórico-metodológico. Política y Sociedad, 47(1), 45-65.

Foro de Vida Independiente y Divertad. (2009). ¿Qué es el FVID? Recuperado de http:// forovidaindependiente.org/que-es-el-fvid/

Galgano, F. (2005). La globalización en el espejo del derecho. Buenos Aires: Rubinzal-Culzoni.

García, F., Moreno, O. y Rodríguez, F. (2015). Problemas del mundo y educación: hacia una ciudadanía planetaria. En B. Borghi, F. García y O. Moreno (Eds.), Novi Cives. Cittadini dall'infanzia in poi (pp. 33-41). Bologna: Pàtron Editore. 
Giddens, A. (2000). Un mundo desbocado: los efectos de la globalización en nuestras vidas. Madrid: Taurus.

Goyes Moreno, I. e Higalgo Oviedo, M. (2012). ¿Los principios del derecho laboral y la seguridad social dinamizan la jurisprudencia constitucional en Colombia? Entramado, 8(2), 168-183.

Guevara, D. A. (2003). Globalización y mercado de trabajo en Colombia: algunas consideraciones en el marco de la flexibilización laboral. Reflexión Política, 5(10). Recuperado de https://revistas.unab. edu.co/index.php/reflexion/article/view/704

Ianni, O. (2006). Teorías de la globalización. Ciudad de México: Siglo XXI editores.

Icontec. (2008). Guía técnica colombiana 180: responsabilidad social. Recuperado de https://tienda. icontec.org/wp-content/uploads/pdfs/GTC180.pdf

Ministerio de Trabajo y Best Buddies Colombia. (2016). Guía para el proceso de inclusión laboral de personas con discapacidad. Recuperado de http://www.mintrabajo.gov.co/ documents/20147/59111836/GUIA+PARA+EL+PROCESO+DE+INCLUSION+LABORAL+DE+P CD.pdf/1d8631c0-58d5-8626-69cb-780bl69fcdf7?version=1.0

Organización Internacional del Trabajo. Ginebra. (1983). Convenio 159 junio 20 Convenio sobre la readaptación profesional y el empleo (personas inválidas).

Palacios, A. (2008). El modelo social de discapacidad: orígenes, caracterización y plasmación en la Convención Internacional sobre los Derechos de las Personas con Discapacidad. Madrid: Cinca.

Pipitone, U. (1996). Los nuevos sujetos regionales: raíces históricas y reordenamiento mundial. En A. Borja, G. González y B. Stevenson. (Coords.), Regionalismo y poder en América: los límites del neorrealismo (pp. 95-129). Ciudad de México: CIDE-Porrúa.

Rubio, R. (2007). Los ciudadanos, ¿̇protagonistas de la globalización? En G. Ramírez (Ed.), El derecho en el contexto de la globalización (pp. 243-273). Bogotá: Universidad Externado.

Sen, A. (2000). Desarrollo y libertad. Barcelona: Planeta.

Stiglitz, J. (2010). El malestar en la globalización. Madrid: Taurus.

Verdugo, E., Yepes, M. R., Paz, A., Sánchez, A. y Monico, M. (2016). Análisis desde la demanda laboral frente a los perfiles ocupacionales de las personas con discapacidad visual en Colombia, 20152016. Recuperado de http://www.inci.gov.co/sites/default/files/transparencia/asistencia_tecnica/ pdf/2017/ANALISIS\%20DESDE\%20LA\%20DEMANDA\%20LABORAL\%20FRENTE\%20A\%20LOS\%20 PERFILES\%20OCUPACIONALES\%20DE\%20LAS\%20PERSONAS\%20CON\%20DISCAPACIDAD\%20 VISUAL\%20EN\%20COLOMBIA\%2C\%202015-2016.pdf 